Dainton-and in reality, the two documents have more in common than first meets the eye--is the assumption that whatever framework is eventually evolved for the channelling of public funds to civil research, the final decision will be made in confidence, by government officials or members of the research councils sworn in advance to secrecy. Over the past few years, it has become apparent that the habit of secrecy has been one of the most serious weaknesses in the apparatus of the research councils. It is true that the Science Research Council in particular, and the Medical Research Council to a lesser extent, have built up elaborate networks for giving advice on the expenditure of money, but this does not entirely dispose of the fear that all of these organizations would be much sharper, and by extension more productive, if they were more ready to encourage public discussion within the scientific community of important policy issues. The Rothschild recipe would necessarily be still less open to opinion from outside. It would be timely if the meeting next week at Strathclyde were to pay some attention to the question whether these are circumstances in which the fullest benefits may be won from the opportunities created in the past few years not merely in agriculture, medicine, on the continental shelf and in the social sciences but also in important fields of industrial research such as computers, data processing, telecommunications and transport. Scientists are fond of saying that war is too important to be left to generals. Is there not a possibility that science is too important to be left to the scientific advisers? What this implies is that the conference at Strathclyde would be well advised to broaden its sights so as to open the wider question of how best to exploit science for the national and even international good. It will be noticed in passing that the Rothschild recipe says nothing about the role of science in higher education, in civilian industry and in defence.

\section{The Duke and IPG}

IN the past fifteen years, the Duke of Edinburgh has enlivened British life in several ways. He has been outspoken about the British press and doubts still linger whether it was he who sprinkled photographers with water at the Chelsea Flower Show. He has been and is still a powerful supporter for the noble cause of the conservation of mammals in Africa. In his time, he has upbraided British industry for failing to make the fullest use of the technology at its disposal. More recently, and perhaps too trendily, he has taken to echoing some of the wilder statements about the future of the British environment. Just before Christmas, he committed himself somewhat tactlessly to the common but mistaken belief that the British population is well on the way to becoming intolerably large. The complaint, of course, is that it is now much harder than it used to be in the 1930s for people to make their way to the beaches in the summer, that city streets are more crowded than they have ever been and that there are many circumstances in which it seems as if the pressure of industry on the environment has sacrificed important amenity. Because people are almost always associated with these developments, it is natural that the growth of population should be blamed.
The trouble is that the analysis is mistaken and that population growth is merely a scapegoat.

In the first place, it is important that the number of births each year in the United Kingdom has been falling steadily since the mid-1960s. At the peak, in 1966, there were 980,000 births. In 1970, the number of births had declined by almost ten per cent. It is true that in the years immediately ahead, the post-war bulge may bring about an upward trend, but this could well be compensated for by a decrease of fertility. So why does the population of the United Kingdom continue to increase? Two years ago, the Government Actuary was estimating that the population would have grown from 56 million at present to 59.3 million in 1980, 63 million in 1990 and 68 million by the turn of the century, but he has since been forced by more recent trends to lower his sights. Whatever the uncertainties, however, there is no doubt that the most important single reason for the growth of population in countries such as Britain is the continuing reduction of mortality among adults. Of the extra 12 million people likely to be alive at the turn of the century, nearly three-quarters will be people of working age or those who have retired. If progress in the treatment of cancer and heart disease is as fast as some people hope, the population could grow still faster but all the extra increase will consist of middle-aged people. This is why those who complain (as the Duke of Edinburgh was doing) at the growth of the British population should be required first of all to recognize that the increase of which they complain consists largely of older people. Do they seriously bemoan increased longevity? And although there is a case for thinking of the use of taxation for restraining fertility in developing countries, what reason is there to think that such devices would have that effect in present circumstances in Britain and similarly developed countries? Might it not be more constructive to explore instead schemes for helping people stay at work beyond the ages now considered proper for retirement?

\section{Years Ago}

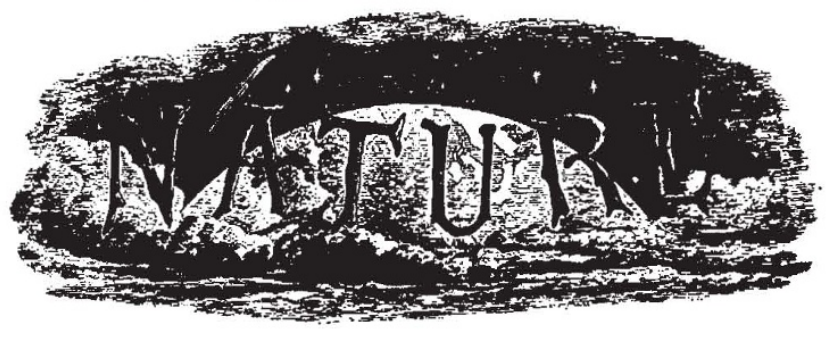

DR. Hor, in a paper read before the Wisconsin Academy of Sciences, Arts, and Letters, remarks, in reference to the mammals of Wisconsin, that the elk existed in that State as late as $186_{3}$, but is now probably extinct. The moose is still found in considerable numbers. The last buffalo was killed in 1832 . Antelopes were also found in Wisconsin in the time of Father Hennepin, although now, of course, driven far to the west. Most of the wild animals are diminishing very rapidly in number, the panther and deer being almost exterminated. The otter and beaver, however, are very persistent. The last wild tur key was killed in $r 846$ near Racins.

From Nature, 5, 191, January 4, 1872 